\title{
Gene polymorphisms in APOE, NOS3, and LIPC genes may be risk factors for cardiac adverse events after primary CABG Sandra Eifert*1, Astrid Rasch ${ }^{1}$, Andres Beiras-Fernandez ${ }^{1}$, Georg Nollert ${ }^{1}$, Bruno Reichart ${ }^{1}$ and Peter Lohse ${ }^{2}$
}

\begin{abstract}
Address: ${ }^{1}$ Department of Cardiac Surgery, Ludwig Maximilians University Munich, Germany and ${ }^{2}$ Department of Clinical Chemistry, Ludwig Maximilians University Munich, Germany

Email: Sandra Eifert* - seifert@med.uni-muenchen.de; Astrid Rasch - Astrid.Rasch@med.uni-muenchen.de; Andres Beiras-

Fernandez - abeiras@med.uni-muenchen.de; Georg Nollert - georg.nollert@siemens.com; Bruno Reichart - breichart@med.uni-muenchen.de; Peter Lohse - plohse@med.uni-muenchen.de

* Corresponding author
\end{abstract}

Published: 19 August 2009

Journal of Cardiothoracic Surgery 2009, 4:46 doi:10.1 186/1749-8090-4-46
Received: 24 March 2009

Accepted: 19 August 2009

This article is available from: http://www.cardiothoracicsurgery.org/content/4/I/46

(c) 2009 Eifert et al; licensee BioMed Central Ltd.

This is an Open Access article distributed under the terms of the Creative Commons Attribution License (http://creativecommons.org/licenses/by/2.0), which permits unrestricted use, distribution, and reproduction in any medium, provided the original work is properly cited.

\begin{abstract}
Introduction: Coronary artery disease progression after primary coronary artery bypass grafting may, beside classical atherosclerosis risk factors, be depending on genetic predisposition.
\end{abstract}

Methods: We investigated 192 CABG patients (18\% female, age: $60.9 \pm 7.4$ years). Clinically cardiac adverse events were defined as need for reoperation $(n=88 ; 46 \%)$, reintervention $(n=58$; $30 \%)$, or angina $(n=89 ; 46 \%)$. Mean follow-up time measured $10.1 \pm 5.1$ years. Gene polymorphisms (APOE, NOS3, LIPC, CETP, SERPINE-I, Prothrombin) were investigated separately and combined (gene risk profile).

Results: Among classical risk factors, arterial hypertension and hypercholesterinemia significantly influenced CAD progression. Single ApoE, NOS3 and LIPC polymorphisms provided limited information. Patients missing the most common $A p o E$ \&3 allele $(5,2 \%)$, showed recurrent symptoms $(p=0,077)$ and had more frequently reintervention $(p=0,00 \mathrm{I})$. NOS3 a allele was associated with a significant increase for reintervention $(p=0,04 \mathrm{I})$ and recurrent symptoms $(p=$ 0,042).

Homozygous LIPC patients had a higher reoperation rate $(p=0.049)$.

A gene risk profile enabled us to discriminate between faster and slower occurrence of cardiac adverse events $(p=0.0012)$.

Conclusion: Single APOE, LIPC and NOS3 polymorphisms permitted limited prognosis of cardiac adverse events in patients after CABG. Risk profile, in contrast, allowed for risk stratification.

\section{Background}

Coronary artery disease (CAD) is a multifactorial disorder, accounts for roughly one-half of all cardiovascular deaths, and is a major cause of morbidity and mortality. Classical risk factors for CAD such as smoking or alterations in lipid metabolism are well known for decades to 
increase the incidence $[1,2]$. Patient counselling and medical therapy of risk factors have become the basis for secondary CAD prevention after primary coronary artery bypass grafting (CABG). Appearance of cardiac adverse events after primary CABG is frequent and leads to recurrent angina, myocardial infarction, and the need for reintervention.

Apolipoproteins play a major role in lipid metabolism. They transfer water insoluble lipids in their soluble state and enable lipid transport mechanisms. Furthermore, they may act as ligands for lipid receptors. Apolipoprotein $\mathrm{E}$ (ApoE) is a ligand for the low density lipoprotein (LDL) receptor and regulates catabolism of lipoproteins. ApoE is also the main protein component of the very low density lipoproteins (VLDL) and high density lipoproteins (HDL). ApoE polymorphisms generate more than 10 percent of the interindividual difference of plasma cholesterol. There are several forms of ApoE. Among them, ApoE4 has a higher and ApoE2 much lower affinity to the LDL receptor. That is the reason, why lipoproteins of $\varepsilon 4$ carriers disappear much faster from plasma. Consecutively, that leads to downregulation of hepatic LDL receptor, resulting in rise of plasma LDL cholesterol. Therefore, ApoE4 may potentially be considered atherogenic, while ApoE2 seems to show a protective effect. That explains the higher cardiovascular risk of $\varepsilon 4$ carriers [3]. Baroni et al., demonstrated correlation between ApoE4 polymorphism and the incidence of CAD [4].

Dysfunction of the vascular endothelium, defined as impaired nitric oxide (NO) activity, may also play a substantial role in the initiation and progression of atherosclerosis $[5,6]$. Most important in this regard appears to be activity or quantity of the enzyme endothelial nitric oxide synthase (eNOS). Several single nucleotide polymorphisms (SNPs) have been described in the NOS3 gene and some of them have been associated with cardiovascular diseases such as 786T/C and 894G/T polymorphism. The $786 \mathrm{CC}$ allele is connected to a reduced gene transcription and probably connected to a decreased NO production. C allele seems to be associated to a higher atherosclerotic risk and coronary spasm [6]. Wang et al. could demonstrate a significantly higher incidence of the rare homozygous eNOS 4a allele in patients with significantly stenosed peripheral arteries. If $894 \mathrm{~T}$ allele is present in $894 \mathrm{G} / \mathrm{T}$ polymorphism eNOS activity may be impaired [5]. This polymorphism may also influence NO release of thrombocytes. We investigated the insertion/deletion polymorphism in intron 4 . It is located on chromosome $7 \mathrm{q} 36$.

Hepatic lipase (LIPC) is a lipolytic enzyme synthesized in hepatocytes playing a major role in HDL metabolism. It takes part in hydrolysis of triacylglycerides and phosphol- ipids of $\mathrm{HDL}_{2}$ into antiatherogenic, cholesterol rich $\mathrm{HDL}_{3}$ as well as catalysation of hydrolysis of big triacylglyceride rich LDL into small, compact, and atherogenous LDL particles. There is a positive correlation between concentration of small, compact LDL and LIPC activity [7].

The LIPC gene is located on chromosome 15 (q21-q23). De Andrade et al., showed a significant correlation between male carriers of a LIPC polymorphism and a higher CAD risk independently of conventional risk factors. The $\mathrm{C} 202 \mathrm{G}$ polymorphism may also be associated with higher triglyceride and lower HDL levels [7].

The influence of the classical risk factors and of genetic polymorphisms, whose protein products play a role in lipid metabolism, coagulation, and nitric oxide metabolism, on the appearance of cardiac adverse events in patients after CABG, who receive contemporary medical treatment, is still unknown.

We hypothesized that CAD risk factors, perioperative parameters, and a genetic predisposition determine the occurrence of adverse cardiac events after primary CABG in individual patients. The hypothesis was tested by retrospectively investigating a group of patients, which underwent primary CABG at our institution more than five years ago. Genetic polymorphisms known to be risk factors for CAD were determined in this patient cohort. Reoperations, reinterventions, and angina at follow-up served as clinically relevant cardiac adverse events.

\section{Methods \\ Patients}

One-hundred-and-ninety two patients, who underwent their first isolated CABG between 1979 and 1999, were investigated. Demographic data and medical therapies at the time of prior CABG are listed in Table 1. All patients made a follow-up visit at our Department between March and October 2007. After written informed consent was given, EDTA blood was drawn for genetic analyses. Reoperation for CAD, reintervention (PTCA and/or stenting and/or hospital admission for myocardial infarction), angina at the time of follow-up, and a combined endpoint of the three previous ones, further referred to as recurrent symptoms were defined as cardiac adverse events. Most patients $(\mathrm{n}=137 ; 71 \%)$ had either a second CABG $(\mathrm{n}=$ $88 ; 46 \% ; 9.3 \pm 3.3$ years p.o. $)$, a reintervention $(\mathrm{n}=58$; $30 \% ; 10.4 \pm 5.9$ years p.o.), or suffered from an angina at follow-up ( $\mathrm{n}=89 ; 46 \% ; 12.6 \pm 5.8$ years p.o). All patients received medical therapy at follow-up. Aspirin (87\%), beta blockers $(70 \%)$, statins (50\%), ACE inhibitors (35\%), and calcium antagonists (24\%) were most commonly prescribed. Patients with progression of CAD were more likely to receive intensified therapy with ACE inhibitors $(\mathrm{p}=0.04)$, and beta blockers $(\mathrm{p}=0.008)$. 
Table I: Demographics of patients and medical therapy at the time of primary CABG

\begin{tabular}{lc}
\hline Patients [\#] & 192 \\
\hline Female [\#] & $34(18 \%)$ \\
\hline Age [Years] & $60.9 \pm 7.4$ \\
\hline Ejection fraction [\%] & $63.0 \pm 14.5$ \\
\hline NYHA Class & $3.0 \pm 1.0$ \\
\hline Bypasses [\#] & $2.4 \pm 1.0$ \\
\hline Left internal thoracic artery grafts [\#] & $1.0 \pm 0.5$ \\
\hline Saphenous Vein Grafts [\#] & $1.5 \pm 1.0$ \\
\hline Additional Grafts [\#] & $0.4 \pm 0.5$ \\
\hline Aspirine Intake [\%] & 75 \\
\hline Beta blockers [\%] & 70 \\
\hline Statins [\%] & 35 \\
\hline ACE Inhibitors [\%] & 24 \\
\hline Calcium Channel Blockers [\%] & 50 \\
\hline
\end{tabular}

\section{Genetic analyses}

Polymorphisms in genes coding for factors involved in lipid metabolism: apolipoprotein E (APOE) $[4,8]$, hepatic lipase (LIPC) [7], and cholesteryl ester transfer protein (CETP) [9], the NO-donor system: endothelial NO synthase (NOS3) [6], and the coagulation system: plasminogen activator inhibitor 1 (SERPINE-1) [10], coagulation factor V (F5) [11], and coagulation factor II (prothrombin (F2) [12] previously described to play a role in the development of CAD were chosen. The genes investigated, their polymorphisms, function as well as the primer sequences are shown in Additional File 1.

\section{Restriction Fragment Length Polymorphism (RFLP) Analysis}

To investigate the selected seven polymorphisms, restriction fragment length polymorphism (RFLP) analysis was used. The patients genomic DNA was isolated from a 200$\mu \mathrm{l}$ aliquot by means of the QIAamp blood mini kit (Qiagen, Hilden, Germany). The PCR reactions contained $5 \mu \mathrm{l}$ PCR buffer (ABgene, Hamburg, Germany), $5 \mu$ d dNTPMix (Fermentas Life Sciences, St. Leon-Rot, Germany) as well as $1 \mu \mathrm{l}$ forward and $1 \mu \mathrm{l}$ backward primer (400 nmol; Thermo Electron Corporation, Ulm, Germany) in a volume of $50 \mu$ l containing about 150-200 ng of genomic
DNA. Depending on the specific polymorphism, the PCR was comprised of an initial denaturation step (15 minutes at $95^{\circ} \mathrm{C}$ ), 35 to 40 cycles of $95^{\circ} \mathrm{C}$ for 20 to 30 seconds, 58 to $72^{\circ} \mathrm{C}$ for 20 to 30 seconds, and of $72^{\circ} \mathrm{C}$ for $30 \mathrm{sec}$ ).

The restriction digests were performed in a $10-\mu$ l volume containing the restriction enzyme (Fermentas Life Sciences, St. Leon-Rot, and New England BioLabs, Frankfurt am Main, Germany), $1 \times$ restriction buffer, and the PCR product. The digests were incubated overnight at $37^{\circ} \mathrm{C}$ and analysed by electrophoresis in a 1,5-3\% agarose gel which was subsequently stained with ethidium bromide. Details of the polymorphisms analyzed are summarized in Additional File 1.

\section{Risk profile}

Because SNPs had a relatively low prevalence in our limited patient cohort and CAD is a multifactorial disease, we constructed a risk profile. Carriers of the risk profile were defined as having one of the following polymorphisms: hetero- or homozygous for the variants of $e$ NOS $4 a b$, the ApoE allele combination 2/4 or 4/4, homozygous expression of LIPC variant, homozygous expression of the CETP variant, and hetero- or homozygosity for the prothrombin G20210A variant. Patients had to be homozygous for PAI$15 \mathrm{G}$ insertion.

\section{Statistics}

For statistical data analysis Microsoft ${ }^{\oplus}$ EXCEL 2002 and SPSS for Windows (Version 12.0, SPSS Inc., Chicago, IL, USA) were used. The primers for the PCR analyses were designed with the help of the computer program "PrimerExpress" (Applied Biosystems).

Values are expressed as mean and standard deviation of mean. The Student's t-Test was used to compare absolute quantitative values. Angina was censored at the day of follow-up, because a precise onset of angina could not be determined. Freedom from reoperation, reintervention, and the combined endpoints (reoperation, reintervention, or angina at follow-up) were calculated by the actuarial method and tested with the log-rank test. Every univariate parameter reaching or approaching significance $(\mathrm{p}<0.2)$ was then tested in a Cox multivariate model using the conditional backward method. $\mathrm{P}<0.05$ was considered significant.

\section{Results and discussion \\ Results}

Preoperative risk factors of CAD and occurrence of cardiac adverse events

Documented risk factors at the time of primary CABG had limited impact on the occurrence of cardiac adverse events. Arterial Hypertension was evident at the time of primary surgery in $73 \%$ of our patients and did significantly 
increase the risk of progression in the sense of reintervention $(p=0.04)$. Eighty two percent of our patients showed hypercholesterinemia at primary CABG. It tended $(\mathrm{p}=$ 0.073 ) to increase the risk of recurrent symptoms. Just $17 \%$ of the investigated CABG patients suffered from diabetes. Significant results are shown in Table 2.

\section{Perioperative parameters and occurrence of cardiac adverse events} (Table 3)

Perioperative parameters demonstrate selection bias for future therapy. Elderly patients ( $>60$ years at primary $\mathrm{CABG})$ were less likely to undergo reoperation $(\mathrm{p}=0.05)$, but tended to be more often selected for reinterventions $(p=0.15)$. Moreover, patients with 3 or more bypasses had less reoperations than patients with 2 or less $(\mathrm{p}=$ $0.005)$.

Gene polymorphisms and occurrence of cardiac adverse events (Table 4)

Out of seven polymorphisms, the following single gene polymorphisms showed significant results and therefore, will results will be restricted to these single polymorphisms: Mutation of $e$ NOS increased the risk for reinterventions $(0.041)$ and for recurrent symptoms $(\mathrm{p}=0.042)$. A similar effect on reinterventions (0.001) and recurrent symptoms (0.077) was observed in patients missing the most common type 3 allele of ApoE. Patients homozygous for the LIPC mutation had a higher incidence of reoperations $(\mathrm{p}=0.049)$.

\section{Distribution of the three ApoE alleles}

Detailed results of the ApoE alleles are demonstrated in Table 5 Patients, who miss the most common allele $\varepsilon 3$ of ApoE $(5.2 \%)$, showed recurrent symptoms $(p=0.077)$ and had more frequently to undergo a reintervention $(p=0.001)$.

\section{Distribution of eNOS $4 a b$ polymorphism}

The homozygous genotype bb (wild type = insertion/ insertion) of $e N O S 4 a b$ insertions/deletion polymorphisms was found in $73.4 \%$. The rare allele a with deletion showed a level of $26.6 \%$ of patients, but only $1.6 \%$ had homozygous genotype aa (deletion/deletion) and
25\% had heterozygous genotype ab (deletion/insertion). Results are depicted in Table 6.

The a allele of NOS3 was associated with a significantly risk increase of reintervention $(\mathrm{p}=0.041)$ and recurrent symptoms ( $\mathrm{p}=0.042)$. Only $5.1 \%$ of patients with allel a, were free of symptoms after 15 years. Carrier of heterozygous expression had a 30\% higher likelihood of reoperation, meanwhile patients with homocygous expression were $30 \%$ more likely, not to undergo a reoperation ( $\mathrm{p}=$ $0,04)$.

\section{Distribution of LIPC genotypes in regard to $C \rightarrow G$ exchange at codon} 202

Analyses showed a higher incidence of reoperation in patients with homozygous genotype $(\mathrm{p}=0.049)$. Table 7 shows the distribution of LIPC genotypes in our patient's population.

Risk profile and occurrence of cardiac adverse events (Figure I) Patients with the risk profile had significantly more reoperations (0.012) and were more likely to have recurrent symptoms (0.0012). The incidence of percutaneous interventions were not different among groups ( $p=0.38)$. However, multivariate Cox regression analysis revealed that only the risk profile had significant impact on the progression of CAD $(\mathrm{p}=0.004)$.

\section{Discussion}

In our study, we investigated a subset of gene polymorphisms known from other investigations as suspects in the development of CAD. Occurrence of cardiac adverse events after primary CABG was significantly influenced by genetic polymorphisms; among the seven evaluated polymorphisms ApoE and $e$ Nos variants had the highest impact on reoperations and reinterventions.

\section{ApoE Polymorphism}

Several studies focused on the effects of $A p o E$ after cardiopulmonary bypass and reported a higher incidence of inflammation [8] and nephropathy [13] in patients with the $\mathrm{E} 4$ allele; depending on the trial more or less neurological sequelae were seen with the E2 allele [14,15]. In

Table 2: Preoperative arterial hypertension and hypercholesterinemia in correlation to occurrence of cardiac adverse events

\begin{tabular}{|c|c|c|c|c|c|c|c|}
\hline \multirow[b]{2}{*}{ Factor } & \multirow[b]{2}{*}{ Definition } & \multirow[b]{2}{*}{$\mathbf{n}$} & \multirow[b]{2}{*}{ Outcome } & \multicolumn{4}{|c|}{ Freedom from [\%] at } \\
\hline & & & & 5 years & 10 years & 15 years & $\mathbf{p}$ \\
\hline \multirow[t]{2}{*}{ Hypertension } & Yes & 140 & Reintervention & 90.6 & 81.7 & 66.4 & 0.04 \\
\hline & No & 52 & & 95.2 & 88.9 & 88.9 & \\
\hline \multirow[t]{2}{*}{ Hypercholesterinemia } & Yes & 159 & Combined & 84.4 & 46.2 & 10.0 & 0.073 \\
\hline & No & 33 & & 96.7 & 76.7 & 18.5 & \\
\hline
\end{tabular}

Significant differences are in italics $(p<0.05)$ print. 
Table 3: Perioperative parameters and occurrence of cardiac adverse events

\begin{tabular}{|c|c|c|c|c|c|c|c|}
\hline \multirow[b]{2}{*}{ Factor } & \multirow[b]{2}{*}{ Definition } & \multirow[b]{2}{*}{$\mathrm{n}$} & \multirow[b]{2}{*}{ Outcome } & \multicolumn{3}{|c|}{ Freedom from [\%] at } & \multirow[b]{2}{*}{$P$} \\
\hline & & & & 5 years & 10 years & 15 years & \\
\hline \multirow[t]{4}{*}{ Age } & $<60$ years & 110 & Reoperation & 95.3 & 65.7 & 19.9 & 0.052 \\
\hline & $>60$ years & 82 & & 93.8 & 78.7 & 46.3 & \\
\hline & $<60$ years & 110 & Reintervtion & 93.2 & 88.6 & 77.4 & 0.15 \\
\hline & $>60$ years & 82 & & 90.8 & 79.1 & 58.1 & \\
\hline \multirow[t]{2}{*}{ \# of bypasses } & $<3$ & 110 & Reoperation & 91.6 & 61.8 & 24.8 & 0.005 \\
\hline & $\geq \mathbf{3}$ & 82 & & 98.7 & 81.6 & 22.2 & \\
\hline
\end{tabular}

Significant differences are in italics $(\mathrm{p}<0.05)$ or bold $(\mathrm{p}<0.0 \mathrm{I})$ print.

Kuukasjärvi et al. [16] investigated the ApoE E4 allele and found, in contrast to most of the studies, this polymorphism not to be a predictor for reoperation. Interestingly, in our study patients without the most frequent allele E3, thus only having the risk alleles E2 and E4, had a more aggressive type of CAD. In regard to the total population, there is no other gene product, which has such a big influence on the individual cholesterin level such as ApoE. Especially the $\varepsilon 4$ allele is increasing the plasma level of LDL. In various investigations $A p o E$ was associated with a higher incidence of atherosclerosis. Baroni et al conducted a study with 6 polymorphisms influencing the lipid system (ApoE, ApoAI, ApoCIII, ApoB, lipoprotein lipase LPL und LIPC [4]. One hundred and two patients with diagnosed CAD were enrolled and 104 healthy patients served as controls. Significant difference between CAD and healthy patients could be demonstrated for Apolipoprotein E, ApoB and HL. ApoE $\varepsilon 4$ allele was associated with a manifest CAD. Results of our study were similar: patients with deletion of the most common allele $\varepsilon 3$ that means they carry the rare combination of either $\varepsilon 2 / 4$ or $\varepsilon 4 / 4$ (isoform $\varepsilon 2 / 2$ is extremely rare) had more frequently to undergo a reintervention. After incidence is so low (2-3\% of general population), evaluation is limited. Therefore, a higher number of patients would be desirable.

\section{eNOS $4 a b$}

The investigated $\boldsymbol{e N O S}$ variant has been associated with a higher susceptibility to coronary lesions in smokers and NO metabolites were $20 \%$ decreased in patients with the 4 aa variant [5]. For endothelial NOS at least 4 frequent polymorphisms (G894T, Glu298Asp, T786C, and the one used in this study) are well established and described to be risk factors for CAD. The argument of having no specific hypothesis to investigate just one and not all other polymorphisms is valid. Further more, some authors see differences in subgroups, i.e. smokers vs. non smokers and young adults. These oppositional results are frequently seen in genetic studies and may be due to the multi factorial origin of the disease. For instance, in japanese and caucasians similar patterns of $\boldsymbol{e N O S}$ alleles were observed [17], but in afroamericans the incidence is generally much lower. Especially environmental factors are difficult to record such as smoking, which is particularly

Table 4: Genetic Polymorphisms and occurrence of cardiac adverse events

\begin{tabular}{|c|c|c|c|c|c|c|c|}
\hline \multirow[b]{2}{*}{ Factor } & \multirow[b]{2}{*}{ Definition } & \multirow[b]{2}{*}{$\mathrm{n}$} & \multirow[b]{2}{*}{ Outcome } & \multicolumn{3}{|c|}{ Freedom from [\%] at } & \multirow[b]{2}{*}{$P$} \\
\hline & & & & 5 years & 10 years & 15 years & \\
\hline eNos & $b b$ & $|4|$ & Reintervention & 93.9 & 88.7 & 75.9 & 0.041 \\
\hline \multirow[t]{3}{*}{$4 a b$} & $a a / a b$ & 51 & & 87.5 & 67.9 & 62.7 & \\
\hline & $b b$ & $|4|$ & Combined & 89.3 & 56.0 & 13.2 & 0.042 \\
\hline & $a a / a b$ & 51 & & 80.4 & 40.6 & 5.1 & \\
\hline \multirow[t]{2}{*}{ ApoE } & $23 / 33 / 34$ & 182 & Reintervention & 92.3 & 84.5 & 75.1 & 0.001 \\
\hline & $24 / 44$ & 10 & & 90.0 & 64.3 & 32.1 & \\
\hline \multirow[t]{2}{*}{ LIPC } & WW/WM & 144 & Reoperation & 96.4 & 74.6 & 27.5 & 0.049 \\
\hline & $M M$ & 48 & & 89.5 & 54.5 & 9.9 & \\
\hline
\end{tabular}

See Additional File I for abbreviations of polymorphisms. M: Mutation; W: Wildtype. Significant differences are in italics $(p<0.05)$ or bold $(p<0.01)$ print. 
Table 5: Distribution of the three ApoE alleles

\begin{tabular}{lccccccc}
\hline ApoE & $\varepsilon \mathbf{2 / 2}$ & $\varepsilon \mathbf{2 / 3}$ & $\varepsilon \mathbf{3 / 3}$ & $\varepsilon \mathbf{3 / 4}$ & $\varepsilon \mathbf{4 / 4}$ & $\varepsilon \mathbf{4 / 2}$ & Total \\
\hline Number[n] & 0 & 22 & 114 & 46 & 2 & 8 & 192 \\
\hline Percentage[\%] & 0 & 11,5 & 59,4 & 24,0 & 1,0 & 4,2 & 100 \\
\hline
\end{tabular}

Patients, who miss the most common allele $\varepsilon 3$ of $A p o E$ (5,2\%), showed recurrent symptoms $(p=0,077)$ and had more frequently to undergo a reintervention $(p=0,00 \mathrm{I})$.

important in eNOS. In our study, the a allele of $e$ NOS $4 a b$ polymorphism was associated with a significantly higher risk for reintervention and recurrent symptoms.

\section{LIPC C202G}

Enzyme activity of hepatic lipase plays a major role in regulating the lipid metabolism. In the above mentioned study from Baroni et al. in carriers of the $\mathrm{g}$ allele of C202G mutation, a decreased level of HDL cholesterol and increased level of triglycerides was observed [4]. Interestingly, the authors found another independent factor regarding clinical endpoints: carrier of homo- or heterozygous g allele had significantly more frequently a second adverse event. Also our results demonstrate a similar course: patients with homozygous expression of the $\mathrm{g}$ allele $(\mathrm{n}=48)$ needed more frequently a reoperation. For this mutation, Murtomaki et al, demonstrated a binding imbalance towards additional LIPC polymorphisms such as L334F, T457T and C480T). Last is related to a low LIPC activity in CAD patients [18]. That means that C202G mutation is a simple marker for additional LIPC polymorphisms and their mutations.

Recently Taylor and associates [19] reported on the influence of lipoprotein lipase locus on the progression of atherosclerosis in coronary artery bypass grafts and identified the LPL-HINDIII 2/2 genotype as an independent risk factor.

\section{Risk Profile}

After single mutations had a relatively low prevalence in our limited patient cohort and CAD is a multifactorial disease we constructed a gene risk profile according to the

Table 6: Distribution of eNOS 4ab polymorphism

\begin{tabular}{lcccc}
\hline eNOS & $\mathbf{b b}$ & $\mathbf{a b}$ & $\mathbf{a a}$ & Total \\
\hline Number[n] & 141 & 48 & 3 & 192 \\
\hline Percentage[\%] & 73,4 & 25,0 & 1,6 & 100 \\
\hline
\end{tabular}

The homozygous genotype bb (wild type = insertion/insertion) of eNOS $4 a b$ insertions/deletion polymorphisms was found in $73,4 \%$. The rare allele a with deletion showed a level of $26,6 \%$ of patients, but only I, $6 \%$ had homozygous genotype aa (deletion/deletion) and $25 \%$ had heterozygous genotype ab (deletion/insertion).
Table 7: Distribution of LIPC genotypes in regard to $\mathbf{C}$ to $\mathbf{G}$ exchange

\begin{tabular}{lcccc}
\hline LIPC & CC & CG & GG & Total \\
\hline Number[n] & 49 & 95 & 48 & 192 \\
\hline Percentage[\%] & 25,5 & 49,5 & 25,0 & 100 \\
\hline
\end{tabular}

The homozygous genotype bb (wild type $=$ insertion/insertion) of eNOS $4 a b$ insertions/deletion polymorphisms was found in $73,4 \%$. The rare allele a with deletion showed a level of $26,6 \%$ of patients, but only I, $6 \%$ had homozygous genotype aa (deletion/deletion) and $25 \%$ had heterozygous genotype ab (deletion/insertion).

definitions. It was a combination of the alleles with the highest incidence of either one of clinical endpoints: Included was hetero- or homozygous a-allele of $e \mathrm{NOS} 4 a b$ polymorphism, because patients showed a significantly higher risk to get a rentervention or recurrent symptoms. Regarding the ApoE they had to carry $\varepsilon 4$ allele, that means $\varepsilon 2 / 4$ or $\varepsilon 4 / 4$, as it is considered to be potentielly atherogenous, was we could also demonstrate. Homozygous carriers of hepatic lipase were prone to undergo a reoperation and recurrent symptoms. That's why part of the risk gene profile was homozygous expression of the $G$ allele. Homozygous expression of CETP gene polymorphism was included. Additionally, hetero- or homozygous variants of G20210A mutation was chosen, because only 50 and $0 \%$ carriers of these variants were free from recurrent symptoms after 10 and 15 years, respectively. However, a simple gene risk profile constructed out of 7 randomly chosen polymorphisms was more predictive for the advancement of CAD than any cluster of classical risk factors.

Certainly medical therapy, particularly lowering of lowdensity lipoprotein cholesterol levels, has been proven to reduce the advancement of CAD after CABG [20]. Due to the design of our retrospective study, we were unable to prove the beneficial effects of medical therapy, because therapy after primary CABG was determined by the cardiologist and patients with recurrent symptoms received intensified medical therapy. In the investigated patient's cohort $87 \%$ received Aspirine, $70 \%$ were given beta blockers, $82 \%$ of patients received statins, $35 \%$ ACE inhibitors and $24 \%$ took calcium antagonists postoperatively. Likewise, the role of classical risk factors on the CAD progression is difficult to interpret. Risk factors at the time of primary CABG were medically treated as described above; patients stopped smoking and started training programs. Therefore, these classical risk factors lost partially their predictive value. Obviously, we investigated only longterm survivors of CABG surgery, who were willing to cooperate. This selection bias may also limit our results. 

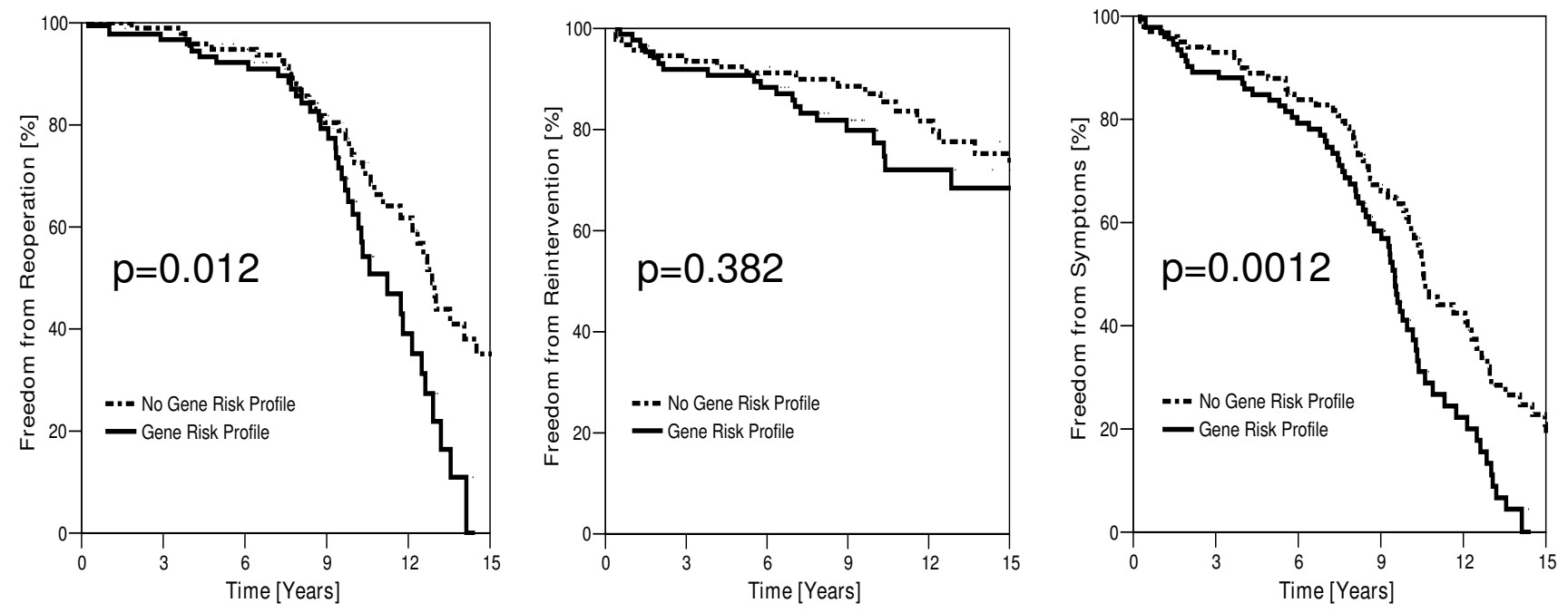

Figure I

Risk profile and occurrence of cardiac adverse events. Out of the seven investigated gene polymorphisms, six were combined for a risk profile (see text). Patients with the risk profile had significantly more reoperations $(0.012)$ and were more likely to have recurrent symptoms (0.00I2). The incidence of interventions (PTCA, stent) were not different among the groups $(p=0.38)$. However, multivariate Cox regression analysis revealed that only the risk profile had significant impact on the incidence of cardiac adverse events $(p=0.004)$.

Knowledge of gene polymorphisms in the era of genomics and their influence on outcome in cardiac surgery is rapidly growing. However, most studies investigated the acute effects of polymorphisms outcome during the postoperative phase. Data on the progression of CAD after primary CABG is rare.

This study is only preliminary, because of its limitations in patient sample size as well as number and choice of investigated polymorphisms. More investigations are warranted and will most likely improve the predictive value of polymorphism tests. We proved the concept, that risk stratification by a simple gene test for the future advancement of CAD after primary CABG is possible. The concept is intriguing, because the detected gene variants give clues to the individual pathophysiology in every single patient in this multifactorial disease [18]. Therefore, this cheap diagnostic tool may hopefully lead to an individualized secondary prevention after primary CABG.

\section{Conclusion}

Classical preoperative risk factors provide little information on appearance of cardiac adverse events, probably because they are so very common among CABG patients. Additionally, most patients were medically treated. Single gene polymorphisms of patients, in the era of whole genome scans, allow a limited prognosis for CAD progression after primary CABG. Risk gene profiles enable risk stratification of CAD progression. They may have the potential to individualize therapy in the future, due to pathophysiological links. Further gene polymorphisms have to be investigated to improve risk stratification.

\section{Competing interests}

The authors declare that they have no competing interests. Institutional review board approval was received before investigations have been started.

\section{Authors' contributions}

SE, AR, GN, BR, PL have made substantial contributions to conception and design, or acquisition of data, or molecular genetic analysis and interpretation of data; SE, $\mathrm{ABF}$ and PL have been involved in drafting the manuscript or revising it critically for important intellectual content; and all authors have read and given final approval of the version to be published. 


\section{Additional file 1}

Investigated genes, their polymorphisms and function, primer and primer sequences. Polymorphisms in genes coding for apolipoprotein $E$ (APOE) [4,8], hepatic lipase (LIPC), cholesteryl ester transfer protein (CETP), endothelial NO synthase (NOS3), and plasminogen activator inhibitor 1 (SERPINE1), coagulation factor V (F5), and coagulation factor II (prothrombin (F2)) were chosen. Details of the polymorphisms are summarized in this additional file 1. Abbreviations: A: Arginin; C: Cytosin; G: Guanin; T: Thymin; HDL: high density lipoprotein; LDL: low density lipoprotein; VLDL: very low density lipoprotein Click here for file

[http://www.biomedcentral.com/content/supplementary/17498090-4-46-S1.ppt]

\section{References}

I. Nabel EG: Cardiovascular Disease. N Engl J Med 2003, 349:60-72.

2. Rossi GP, Maiolino G: Association of gene polymorphisms with coronary artery disease in low- or high-risk subjects defined by conventional risk factors. J Am Coll Cardiol 2004, 44(I):209f.

3. Curtiss LK, Boisvert WA: Apolipoprotein E and atherosclerosis. Curr Opin Lipidol 2000, I I:243-25I.

4. Baroni MG, Berni A, Romeo S, Arca M, Tesorio T, Sorropago G, Di Mario $U$, Galton DJ: Genetic study of common variants at the Apo E, Apo AI, Apo CIII, Apo B, lipoprotein lipase (LPL) and hepatic lipase (LIPC) genes and coronary artery disease (CAD): variation in LIPC gene associates with clinical outcomes in patients with established CAD. BMC Med Genet 2003, 4:8-16.

5. Wang XL, Sim AS, Badenhop RF, McCredie RM, Wilcken DE: A smoking-dependent risk of coronary artery disease associated with a polymorphism of the endothelial nitric oxide synthase gene. Nat Med 1996:4I-5.

6. Buchholz T, Lohse P, Kosian E, Thaler CJ: Vasoconstrictively acting ATIR AII66C and NOS3 4/5 polymorphisms in recurrent spontaneous abortions (RSA). Am J Reprod Immunol 2004, 5I(5):323-8.

7. de Andrade FM, Silveira FR, Arsand M, Antunes AL, Torres MR, Zago AJ, Callegari-Jaques SM, Hutz MH: Association between -250G/A polymorphism of the hepatic lipase gene promoter and coronary artery disease and HDL-C levels in a Southern Brazilian population. Clin Genet 2004, 65(5):390-5.

8. Grunenfelder J, Umbehr M, Plass A, Bestmann L, Maly FE, Zünd G, Turina M: Genetic polymorphisms of apolipoprotein E4 and tumor necrosis factor beta as predisposing factors for increased inflammatory cytokines after cardiopulmonary bypass. J Thorac Cardiovasc Surg 2004, I 28(I):92-7.

9. Chaaba R, Smaoui M, Hammami S, Attia N, Ben Hamda K, Masmoudi AS, Mahjoub S, Bouslama A, Ben Farhat M, Girard-Globa A, Hammami $\mathrm{M}$ : Role of cholesteryl ester transfer protein activity and genetic polymorphism in ischemic heart diasease in type II diabetic patients. Tunis Med 2004, 82(3):282-8.

10. Anvari A, Schuster E, Gottsauner-Wolf M, Wojta J, Huber K: PAI-I 4G/5G polymorphism and sudden cardiac death in patients with coronary artery disease. Thromb Res 200I, I03(2): 103-7.

II. Zahn R, Beeck H, Winkelmann BR, Seidl K, Schneider S, Hellstern P, Senges ]: Prospective cross-sectional study of haemostatic factors in patients with and without coronary artery disease. Blood Coagul Fibrinolysis 2002, I3(2):8I-7.

12. Russo C, Girelli D, Olivieri O, Guarini P, Manzato F, Pizzolo F, Zaia B, Mazzucco A, Corrocher R: G202IOA prothrombin gene polymorphism and prothrombin activity in subjects with or without angiographically documented coronary artery disease. Circulation 200I, I 03(20):2436-40.

13. Mackensen GB, Swaminathan M, Ti LK, Grocott HP, Phillips-Bute BG, Mathew JP, Newman MF, Milano CA, Stafford-Smith M: Perioperative Outcomes Research Group; Cardiothoracic Anesthesiology Research Endeavors (C.A.R.E.) Investigators of the
Duke Heart Center. Preliminary report on the interaction of apolipoprotein E polymorphism with aortic atherosclerosis and acute nephropathy after CABG. Ann Thorac Surg 2004, 78(2):520-6.

14. Gaynor JW, Gerdes M, Zackai EH, Bernbaum J, Wernovsky G, Clancy RR, Newman MF, Saunders AM, Heagerty PJ, D'Agostino JA, et al.: Apolipoprotein $E$ genotype and neurodevelopmental sequelae of infant cardiac surgery. J Thorac Cardiovasc Surg 2003, | 26(6): : 736-45.

15. Silbert BS, Evered LA, Scott DA, Cowie TF: The apolipoprotein E epsilon 4 allele is not associated with cognitive dysfunction in cardiac surgery. Ann Thorac Surg 2008, 86(3):84I-7.

16. Kuukasjärvi P, Tarkka M, Mennander A, Ilveskoski E, Koivisto AM, Laippala P, Mikkelsson J, Karhunen PJ: Apolipoprotein E polymorphism is not a predictor for repeated coronary artery bypass surgery. Scand Cardiovasc J 2005, 39(4):220-4.

17. Wang XL: Cigarette smoking, DNA variants in endothelial nitric oxide synthase gene and vascular disease. Contribution Nephrology 2000, 130:53-67.

18. Murtomaki S, Tahvanainen E, Antikainen M, Tiret L, Nicaud V, Jansen $\mathrm{H}$, Ehnholm C: Hepatic lipase gene polymorphisms influence plasma HDL levels. Results from finnish EARS participants. Arterioscler Thromb Vasc Biol 1997, I7(10): 1879-| 884.

19. Taylor KD, Scheuner MT, Yang H, Wang Y, Haritunians T, FischelGhodsian N, Shah PK, Forrester JS, Knatterud G, Rotter JI: Lipoprotein lipase locus and progression of atherosclerosis in coronary-artery bypass grafts. Genet Med 2004, 6(6):48I-6.

20. Knatterud GL, Rosenberg Y, Campeau L, Geller NL, Hunninghake DB, Forman SA, Forrester JS, Gobel FL, Herd JA, Hickey A, et al.: Long-term effects on clinical outcomes of aggressive lowering of low-density lipoprotein cholesterol levels and low-dose anticoagulation in the post coronary artery bypass graft trial. Post CABG Investigators. Circulation 2000, 102(2):157-65.

Publish with Bio Med Central and every scientist can read your work free of charge

"BioMed Central will be the most significant development for disseminating the results of biomedical research in our lifetime. "

Sir Paul Nurse, Cancer Research UK

Your research papers will be:

- available free of charge to the entire biomedical community

- peer reviewed and published immediately upon acceptance

- cited in PubMed and archived on PubMed Central

- yours - you keep the copyright
BioMedcentral 